\title{
Lessons Learned: One University's Experience In Developing And Revising An AIS Curriculum
}

David R. Fordham (E-mail: fordhadr@jmu.edu), James Madison University

\begin{abstract}
The last decade has seen phenomenal growth in the use of technology and information systems in the field of accounting. In response to this change, many colleges and universities have added a concentration in Accounting Information Systems (AIS) to their accounting programs. This paper describes the processes followed by one comprehensive university to introduce and later revise an AIS concentration program. A surprising finding of the revision process was an unexpected role of the AIS courses in the alumni's career development, -- a finding which was uncovered only by an innovative investigative step of the review and revision process. In light of the results, a model is offered to assist other institutions in improving their curriculum development (and review) process.
\end{abstract}

\section{Introduction}

6 ver the last generation, the field of accounting has undergone a tremendous change relative to the use of information technology. In contrast, accounting education has been relatively slow to adapt to this changing emphasis. For example, a study published in the Review of Accounting Information Systems (Bryant et al, 1999) indicated that of all U.S. AACSB-accredited business schools offering bachelor's degrees in accounting, just over $2 \%$ (only 8 of 350 schools) offered undergraduate programs (majors, minors, concentrations, specialties, etc.) in accounting systems or a field similar to AIS.

Recently, however, this has begun to change. Stone (2002, p.3) notes the growth in the IS section of the American Accounting Association, the growing number of AIS topics on national accounting programs and meetings, rising ratings of AIS journals and papers, and several other measures which seem to indicate that higher education is coming to recognize the essential nature of information systems and technology within the field of accounting.

Institutions desiring to add to the AIS content of their programs face several major challenges. One of these, described by Fordham et al (1997) involves the lack of qualified professors to systems-related courses. Another challenge is deciding what content to add to the curriculum to develop the knowledge and skills required by their accounting graduates. AIS faculty have consistently identified a few broad topic areas that should be emphasized in the first AIS course in an accounting curriculum (Bain et al, 2002). But selecting additional topics to supplement the "core" of AIS knowledge is still problematic.

The remainder of this paper reports on the approach used by one comprehensive university to determine what topics to include in the AIS curriculum. The paper also describes some insightful findings into the perceptions of alumni about how their experience in the program applies to their careers. Because of the importance of the findings, a model is presented for curriculum development (and/or revision) which adds an innovative step to the curriculum process. The paper's intention is to share ideas uncovered by experience - ideas which might not at first be apparent to institutions and faculty considering the addition of AIS content to their curriculum. 


\section{Initiation Of The Original AIS Concentration}

The demographics of the institution is given in Appendix A. The original AIS concentration program was developed in response to requests by several CPA firms recruiting on campus in the mid 1980's. Those firms expressed a preference to hire accounting majors who possessed some knowledge of systems analysis and design, EDP auditing and related computer concepts. The firms were paying premium salaries to graduates who possessed this knowledge and skill.

At the time, no formal survey of recruiters was conducted. The faculty felt they had ample anecdotal evidence from recruiters as well as the observable starting salary offers to those few graduates who possessed the IS expertise (double-majors, for the most part). The faculty to discussed the matter with the institution's administration, and a formal AIS concentration within the accounting major was approved.

For a number of reasons, a formal curriculum development process was followed to determine the program's content. The firms were fairly specific in their requests. And courses already existed in the IS department curriculum covering the knowledge being requested. Further, the field of AIS was still in its infancy as a specialty, and few, if any, resources existed at the time to assist in formal curriculum study.

The firms were asking for additional knowledge, not replacement knowledge. Thus, the concentration curriculum was designed to retain all of the regular accounting coursework, and add the IS courses as a supplement. The knowledge areas mentioned by the recruiters (systems analysis \& design and EDP auditing) existed as standalone courses in the institution's MIS department, but had several prerequisite requirements. If a student took both courses and their respective prerequisites, the student would have completed essentially a double major. Since a double major was already available, the accounting faculty decided to add a middle-ground option: one, but not both, of the primary topics. A four-course concentration would meet this criteria, and also exhibit the advantage of requiring only one additional semester's work beyond the baseline accounting major program of study. The middle-ground option had the additional benefits of requiring no new course creation (easing the approval process and allowing the curriculum to be implemented in a timely fashion), as well as eliminating the need for an extensive curriculum development effort, while simultaneously meeting the expressed needs of the recruiters. The four courses in the concentration were:

1. Systems Analysis \& Design; or alternately, EDP Auditing (the primary skills asked for by the recruiters);

2. Intermediate Information Systems Concepts (a prerequisite for the Systems Analysis and Design course), or alternately, Telecommunications or Computer Security (prerequisites for the EDP auditing course)

3. Database Design Concepts (a prerequisite for both EDP Auditing and Systems Analysis \& Design);

4. Introductory Computer Programming (a prerequisite for the database course).

Note that the majority of the four-course set was determined by the MIS department's prerequisites for the desired courses in analysis \& design or EDP auditing, rather than an expressed need for the material in the other three courses.

In spite of the obvious flaws in the procedure used to develop the initial curriculum, the preliminary combination of courses did indeed impart value to the AIS graduates. They reported higher performance, quicker advancement, and better opportunities than their peers who did not have the AIS concentration. As word of their success spread, the demand for AIS majors among the recruiters rose quickly. As demand for the graduates rose, salaries also rose, and student demand for the program increased dramatically. After several years, the size of the AIS concentration reached the point where the accounting department was able to justify dedicating its own resources to the program. Since so much of the original concentration had been constrained by the MIS prerequisites -- a necessity eliminated by bringing the program into the accounting department - the faculty decided to do a full-fledged curriculum review to properly determine the contents of the program. 


\section{Curriculum Design: Multiple Input Approach}

Most curriculum design efforts begin with a review of normative literature and/or consideration of what "other institutions are doing". At the time of the curriculum review, there were only a handful of AIS programs in existence. Making matters more difficult was the fact (still hampering institutions today) that there is little formal research into exactly what an AIS program should look like. So rather than the traditional curriculum design process, the faculty elected to begin by using other sources to determine the "ideal" AIS curriculum. Chief among these sources were the institution's constituencies, who had been instrumental in the origin of the AIS program in the first place.

Executive Advisory Board: The accounting program already had a functioning executive advisory board. These upper-level executives were asked for their input. The comments by the board were useful in confirming an expected increase in demand for AIS majors, continued higher salaries, and also that the employers were quite happy with the skill set and knowledge possessed by recent graduates of the current program. But when it came to consideration of possible changes, the board expressed reservations about any curriculum modification. In their opinion the current curriculum was fine as it stood. In the words of one member, "If it ain't broke, don't fix it." To gain additional detail, the board members were asked to provide names of the individuals at their firms who directly supervised the recent AIS hires: operational and line managers who oversee the day-to-day operations in which AIS majors would be employed. These practitioners were then contacted in an attempt to more narrowly define the skills and knowledge needed.

Input From Recruiters: Faculty also collected data from current recruiters and companies who did not currently recruit on campus but who potentially might hire AIS majors. The recruiters were asked to specify the skill set and knowledge possessed by an "ideal" candidate for an AIS position.

Input From Alumni And Graduates: Faculty also contacted more than 100 AIS graduates from the program who were in the early and middles stages of their professional careers. These professionals were asked to rate the skills acquired during the program and describe any skills which they needed on the job, but which were not provided as part of their educational experience. They were also asked numerous other questions about the program and recommendations for revision and improvement.

\section{Draft List Of AIS Skills And Knowledge}

Once the data was collected, the faculty condensed the responses to a draft set of AIS skills. The consistency among the constituencies was surprising. It must be noted that at this point, the faculty had not unduly influenced the process by interjecting any input from literature, other institutions' experience, or research as to what an AIS program should be. The draft skills list was developed purely from the institution's constituencies.

\section{Comparison With Literature}

After the list was compiled, the faculty compared it to the normative AIS literature (AAA, Bain et al, Moscove et al; Summers; Ingram; Murthy \& Wiggins, etc.) and to the AIS curriculum at other schools with an AIS concentration program (Bryant $e t a l$ ). This comparison uncovered several major discrepancies between what our constituencies were asking for, and what the literature suggested and what other schools were doing. These discrepancies, of course, can be easily explained by the differences between institutions and their respective employer pools, and the resultant experience of alumni on their jobs. Recruiters and firms might be attracted to one institution over another because of the strengths of students in a particular area. Once word circulates about the strengths of the students, other employers seeking strength in that area would naturally gravitate to that institution, while employers seeking strengths in other areas might bypass the school in favor of another institution whose students display strengths in other areas. Thus, any list of skills valued highly by a recruiter pool and graduates at a given institution is likely to be highly biased in favor of that institution's existing strengths, and biased against that institution's weaknesses. Further, it is natural for students finishing classes in telecommunications and computer security to gravitate in their careers towards jobs wherein those skills are used. Thus, it should be expected that they 
would value the skills learned and being used in those jobs. Because they possessed the skills, they performed well in those jobs, leading recruiters and supervisors to endorse the skills as necessary. ${ }^{1}$

The question arose: Should the curriculum continue to perpetuate the skill set which was developed almost by accident (the initial AIS curriculum which was highly influenced by the MIS department's constraints), or should the curriculum be modified to more closely match the normative models being reported by the literature and followed by a number of other institutions?

In light of the faculty's satisfaction with the existing recruiter base and even the potential recruiter base polled in the exercise, some faculty were hesitant to ignore the recommendations of such a large majority of the institution's constituencies. Other faculty were in favor of a move towards the normative models being proposed in the literature, presumably prepared under more rigorous conditions and subjected to wider review. Still others were in favor of combining the lists and judiciously picking from the topics based on faculty experience.

\section{Benefit Of Investigation Over Mere Reconciliation}

At this point in the process, the faculty could have proceeded to develop the AIS program curricula by following one of three obvious courses of action:

1. Adopt the list of skills derived from constituency input;

2. Adopt a list derived from the normative literature and experiences of other institutions; or

3. Combine the two lists, using faculty judgment about which topics to include or exclude.

Although option (3) tends to be most popular anecdotally, it is fortuitous that the faculty in this instance elected not to follow any of the three options, but rather to investigate in more detail the reason for the discrepancy between the constituency skill list and the normative literature (and the faculty's expectations!). The faculty went back to the recruiters, supervisors, and alumni, and delved more deeply into why the discrepancies existed. If it could be confirmed that the discrepancy was indeed due to self-selection, the choice of curriculum direction would be clear and the constituency list would prevail. If the discrepancy existed because of a "gee, we never thought of that" oversight, the faculty would be overlooking potential improvement by sticking with the constituencies list.

The faculty went back to the recruiters and alumni, and presented some suggestions for curriculum revision (in line with the normative models) and asked whether the alumni felt the changes would improve the program, and why or why not. Several hour-long conversations were held to ascertain exactly why the recruiters and alumni valued some subjects highly while the literature had omitted them completely, and why the literature suggested some topics which the recruiters and alumni had failed to mention. The interviews were informal and open-ended.

The results of this "investigation and reconciliation" revealed some very insightful and useful revelations about the roles played by the AIS courses in the careers of the graduates. The faculty would have remained completely unaware of these insights had they not taken the time to more deeply investigate the skills lists.

As an example, two of the changes being considered by the faculty were the elimination of the programming and database courses, -- two highly-technical, hands-on classes which the faculty felt contributed only a negligible amount to a professional accountant's career path. (The basic concepts from these courses were already being covered in the base accounting AIS course, and students taking these two courses complained of their irrelevance to accounting.) To the surprise of the faculty, the alumni vehement expressed the view that the programming course, as well as the database design and development course, remain an essential part of the AIS program. They explained that the course taught them abstract concepts (such as conditional and unconditional branching, process flow, sequence, interruption and return, comparisons, structured design, variable definitions, and

\footnotetext{
1 Hammer (1996) for example, suggests that a good fit between the job environment and a person's preferences will result in greater vocational stability, satisfaction, productivity and creativity, and that individuals are attracted to organizations containing individuals with similar preferences to their own.
} 
other concepts) which the alumni felt helped them immensely in the way they approached situations, tackled problems, and interpreted their environments. They felt the depth they experienced in the database course enabled them to develop a more thorough mental relationship between physical entities and the information system models representing those physical entities, far beyond what they experienced in the baseline AIS course (which covered database development in addition to other material).

In other words, the alumni were expressing the belief that these courses had changed the way they thought and the way they viewed their world. The courses were serving a function historically associated with "liberalstudies" general education courses (logic, thought, analysis, critical evaluation, mental organization, etc.) rather than (or perhaps in addition to) imparting vocational-type skills. This took the faculty by surprise.

Another proposed change was elimination of such highly-technical material as network construction, hardware, and telecommunication systems. But feedback from the alumni again revealed strong feelings that highly technical topics (such as the 7-layer Open Systems Interconnect (OSI) model, private-key/public-key cryptography, telephone system services, and similar subjects which the faculty felt were only tenuously related to accounting) were essential to their career progress and professional development. The deeper investigation once again revealed a new role being played by these courses, too. The alumni recognized that their knowledge of what was happening within the black box of technology had helped them understand how the technology was solving a business problem. By extrapolating this understanding, they felt they were better able to learn and evaluate new technologies as they appeared, and they could better determine whether a new technology would be appropriate for deployment in a given (new) problem situation.

In other words, the technical "training" they were receiving was doing more than merely imparting vocational skills, it was actually enabling a thought process, allowing the graduates to interpret, evaluate, extrapolate, and operate at a higher mental level. In short, the technical-level knowledge enhanced conceptual understanding. It facilitated better "learning after graduation" and helped the alumni cope with the advance of technology years beyond completion of their degree.

These insights and others would not have been revealed without the investigative phase of the curriculum review. Had the faculty merely proceeded to design a curriculum based on the list of skills and knowledge, whether from the constituencies, the normative models, or even a combination of the two, they faculty likely would have missed an important (critically important, by some accounts) opportunity to understand the full impact of the AIS education. By failing to comprehend the surprisingly rich role played by the AIS coursework, the faculty could have unknowingly diminished the effectiveness of the curriculum.

Armed with the knowledge gained by the investigative phase, the faculty came to appreciate the deeper value of certain skills and knowledge. It was apparent from the results that the AIS education was playing a much richer part in the lives and careers of the graduates than had been obvious. By leveraging this knowledge of how

thoroughly their education was affecting student lives, the faculty could not only design a better AIS curriculum, but could also approach the regular baseline accounting curriculum with a view of the wider view and broader horizon.

\section{Summary of Curriculum Development Procedure}

Figure 1 graphically summarizes the procedure used in revising this AIS curriculum, and is being recommended as a model for curriculum review and/or development. 
Figure 1

Procedure for Development Of A Second AIS Course

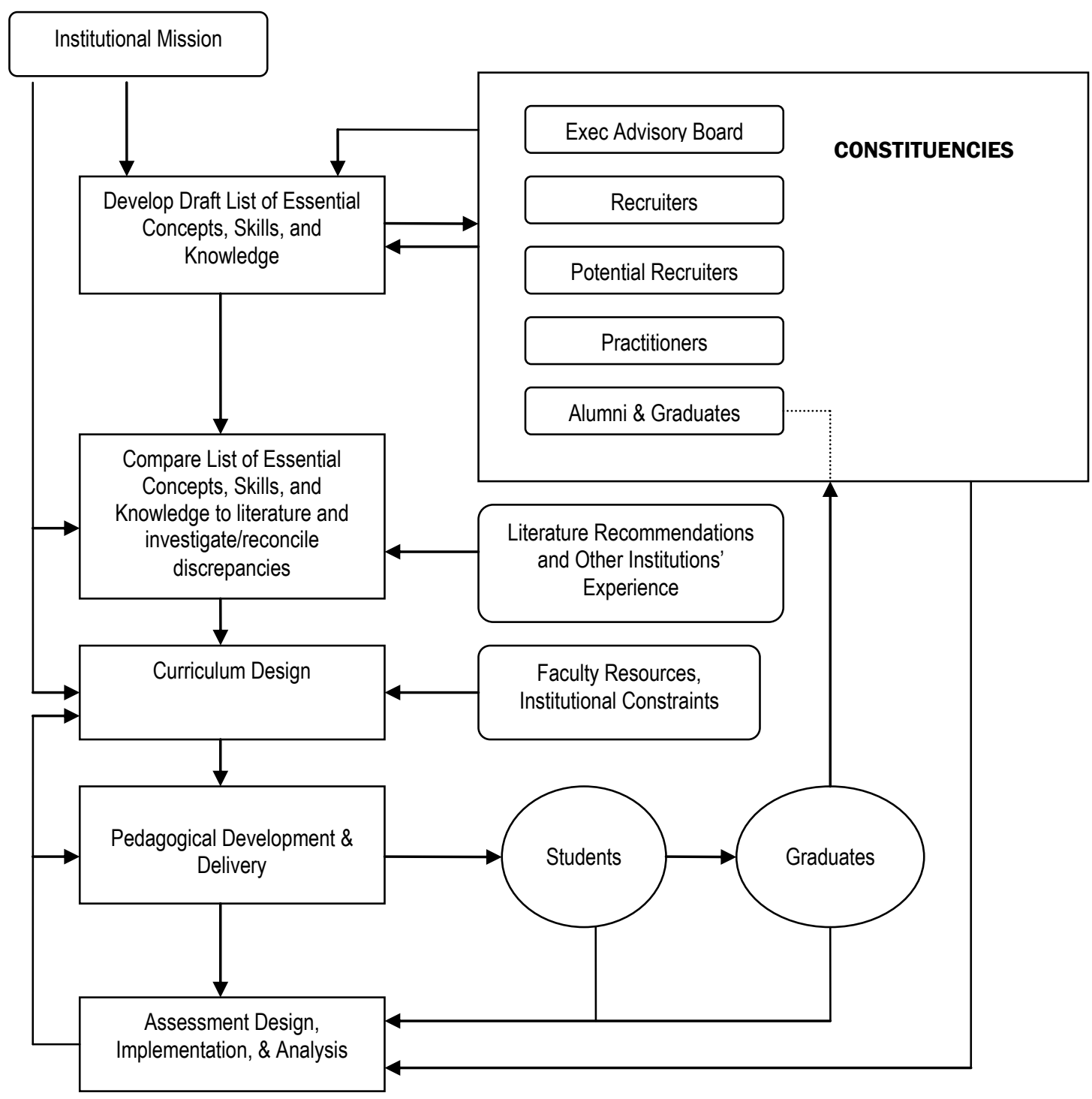

Feedback on Curriculum's Success

Note: The data gathering (from constituencies) and feedback steps should involve more formal collection and analysis methodology than was used in this case. Also, detailed documentation of each step will prove helpful to future curriculum revision and development efforts.

While this model is similar to the process generally followed by many institutions, it is important to note one major feature. The temptation is to embark on a data-gathering effort, (whereby data is collected from (a) constituencies as well as (b) the literature and other institutions) as part of a single comprehensive data-gathering step. The model in Figure 1 notably separates out these two sources, and interjects an innovative intermediate step 
involving investigation and reconciliation of discrepancies between the constituency input and the suggestions/recommendations from the normative literature and other institutions' experience. It is this separate investigative step which revealed the previously hidden roles being served by the educational process in our experience. Other institutions can probably uncover their own "revelations" about why their constituencies might or might not agree completely with the normative literature and/or other institutions' programs.

By looking very closely at how, and more importantly why, the institutional constituencies differ from normative models, faculty can gain insights which allow them to tailor their program to provide an optimum educational experience for their students, beyond merely "meeting the expressed needs" enumerated by surveys, questionnaires, rating forms, and the typical host of data-gathering techniques of traditional curriculum review projects.

\section{Limitations, Caveats, And Hindsight}

Experience is the best teacher. This institution jumped headfirst into offering an AIS concentration based on informal anecdotal evidence, and created a curriculum limited heavily by another department's course prerequisite structure. Recognizing the approach as being sub-optimal (its success notwithstanding), the faculty attempted to follow are more theoretically-sound procedure in their review and modification of the curriculum nine years later.

While the revision procedure (Figure 1) is a major improvement in process over the first curriculum effort, it might be argued that the implementation of the procedure suffered from a research flaw. Much of the evidence gathered from recruiters, alumni, advisory board members, and practitioners in the review was not structured enough to be considered "good" data for statistical analysis. It is admitted that a true statistical analysis was not performed on the responses obtained, primarily because the data was not in a form which readily lent itself to tabulation. Different faculty took notes differently, no uniform instrument was used to solicit responses, no numerical scale or weighting was applied to gauge relative importance. Respondents were simply asked (in many different forms as various faculty members differed in their approach) whether the content was sufficient, desirable, complete, etc., and what their recommendations would be. The were asked for narrative responses and opinions about proposed changes rather than numerical ratings traditionally used in surveys and related investigative endeavors. As a result of the inconsistency in query, the conclusions drawn (about necessary skills and knowledge) might legitimately be questioned by some. (For instance, a rigorous examiner might ask whether the data conclusively determined that network technology is actually required of AIS majors? A forceful argument can be made that without welldocumented responses elicited by a common and uniform instrument allowing statistical analysis, such a conclusion would be suspect.)

The faculty readily recognize this is a drawback to their implementation, and plans are already being made to conduct a more formal, well-structured assessment process as part of the institution's next periodic Academic Program Review. In the meantime, the faculty are strongly convinced that the uniformity, consistency, and highly repetitive nature of the ideas conveyed by the informal comments are sufficient to make useful conclusions about the desired content of the AIS program.

But more importantly, it is felt that the unstructured methodology for data collection is responsible for the unique insights derived. Had respondents simply filled out a survey instrument or applied numerical ratings, the discovery of the useful insights and perceptions of the alumni might never have been revealed, even had free-form comments been solicited. The faculty might been more inclined to accept "statistically valid" numbers in lieu of questioning further.

\section{Conclusions}

Today's AACSB accreditation guidelines recognize that each institution has a mission, constituency, and environment which makes it unique among its peers. It is essential, especially for an AIS program, for an institution to tailor its curriculum to meet the needs of its constituencies. However, the traditional approach to curriculum 
development and review (whereby a skills or knowledge list is developed concomitantly from input from constituencies, the normative literature, and other institutions) has the drawback of possibly overlooking some deeper, perhaps hidden, aspects of the roles played by education in the careers of the graduates.

Learning from the experience of others is a major source of improvement facilitated by a society. It is hoped that by sharing the process we followed in revising our AIS curriculum, both the strengths as well as the weaknesses and limitations, other institutions can avoid our mistakes and develop a much better curriculum than they might in the absence of our example. It is also felt that by sharing the insights and perceptions of our alumni, other institutions can be alert for possible expanded roles of their programs in the careers and lives of their students and graduates.

The procedure recommended in Figure 1 can be used not only for an AIS course, but for generalized curriculum reviews and improvements.

\section{References}

1. Bain, Craig E., Alan I. Blankley, and L. Murphy Smith, "An Examination of Topical Coverage for the First Accounting Information Systems Course", Journal of Information Systems, Volume 16, No. 2, 2002.

2. Bryant, Stephanie M., Judy K. Weishar, and David R. Fordham, "A Survey of Accounting Information Systems Programs in U.S. Colleges and Universities", The Review of Accounting Information Systems, Volume 3, No. 2, pp. 1-11, 1999.

3. Fordham, David R., Stephanie M. Bryan, and Ralph L. Benke, "The Evolution of an Accounting Information Systems Concentration: Concepts and an Example", The Review of Accounting Information Systems, Volume 1, No. 3, pp. 1-9.

4. Hammer, A.L., (ed), MBTI Application: A Decade of Research on the Myers-Briggs Type Indicator, Consulting Psychologists Press (Palo Alto, CA), 1996.

5. Ingram, Robert W., (ed), Computer Integration into the Accounting Curriculum: Case Studies, Coopers \& Lybrand Foundation and the American Accounting Association, Sarasota, 1988.

6. Moscove, Stephen A., Mark G. Simkin, and Nancy A. Bagranoff, Core Concepts of Accounting Information Systems, Wiley and Sons (New York), 1999.

7. Murthy, Uday S., and Casper E. Wiggins, Jr., "A Perspective on Accounting Information Systems Research", Journal of Information Systems, Volume 13, No. 1, pp. 3-6, Spring 1999.

8. Stone, Dan N., "Researching the Revolution: Prospects and Possibilities for the Journal of Information Systems", Journal of Information Systems, Volume 16, No. 1, pp. 1-6, 2002.

\section{Appendix A \\ Institutional Background}

The institution serving as the subject of this paper is a mid-sized comprehensive university in the midAtlantic region of the United States. The university has just over 15,000 undergraduate students and about 2,000 graduate students. It is located in a rural setting approximately three hours from several major metropolitan areas with total population in excess of 10 million. Over $90 \%$ of the student body is made up of traditional resident students, mainly from upper-class professional families. The College of Business comprises approximately onequarter of the university's enrollment (3,600 declared business majors). The College of Business and the Accounting Programs are both AACSB accredited. The accounting program has remained fairly constant in size over the past 15 years, graduating approximately 100-120 majors each year. The university operates a large oncampus recruiting program. Of each year's graduating accounting class, approximately half find employment with the big four accounting firms, another quarter find employment in public accounting with other firms, and a quarter are employed in industry and government. The program maintains a small (10 student) masters degree program. The university is located in a state which has approved the 150-hour education requirement of the Uniform Accountancy Act, but the requirement will not take effect for several years. 